\title{
Starch-jute fiber hybrid biocomposite modified with an epoxy resin coating: fabrication and experimental characterization
}

\author{
${ }^{1}$ Indian Institute of Technology, Roorkee, India, Phone: +91-9634899497, E-mail: akarshverma007@gmail.com \\ ${ }^{2}$ G. B. Pant University of Agriculture and Technology, Pantnagar, India, E-mail: akarshvermaoo7@gmail.com
}

\begin{abstract}
:
In this article, biocomposites derived from a starch-glycerol biodegradable matrix reinforced with jute fibers were fabricated using the wet hand lay-up and compression moulding techniques. Samples having different weight percentages of jute fiber in the starch matrix were analyzed. The fiber's surface was chemically treated by alkaline sodium hydroxide to improve the interphase bonding between the fiber and the matrix. Tensile tests for the composites were done and the sample with highest tensile strength was selected for further tests that included water absorption (WA), scanning electron microscopy (SEM) and thermal analysis (TA). It has been concluded that the ultimate tensile strength was found to be maximum for the composition of $15 \%$ fiber by weight composite as 7.547 MPa without epoxy coating and $10.43 \mathrm{MPa}$ with epoxy coating. The major disadvantage of the biocomposite is its high WA property, which in this study was inhibited by the epoxy resin layer. Herein, the results of various tests done disclose a noteworthy improvement in the overall properties of bio-composite, in comparison to the neat biodegradable starch matrix.
\end{abstract}

Keywords: biocomposite, epoxy resin, jute fiber, microstructure, starch matrix

DOI: $10.1515 / \mathrm{jmbm}-2018-2006$

\section{Introduction}

A composite is a structural material that consists of two or more combined constituents (matrix and reinforcement) at a macroscopic level and is not soluble in each other [1]. In order to meet the ecological objects, both the matrix and reinforcement need to be fully biodegradable to avoid further annihilation of the environment. Although the presently accessible fully "green" composites (biocomposites), do not satisfy all the requirements for automotive components, they tend to be the subsequent innovational materials in the future. There is growing urgency to develop and commercialize new crops, new bio-based products and other innovative technology which do not rely on fossil fuel. That is why biocomposites are becoming one of the most important factors in creating a more ecological future.

Biocomposites are inexpensive, recyclable, possess low density and high strength to weight ratio [2]. Cao et al. [3] investigated the mechanical properties of biodegradable composites reinforced with untreated and alkalitreated bagasse fibers. Mechanical properties of the composite made from alkali-treated fibers are superior to the untreated fibers. Approximately 13\% improvement in tensile strength, $14 \%$ in flexural strength and $30 \%$ in impact strength had been found, respectively. Gilfillan et al. [4] studied the preparation and characterization of composites from starch and bagasse fibers. Different types of tests were conducted on 5 weight percentage $(\mathrm{wt} \%), 10 \mathrm{wt} \%$ and $20 \mathrm{wt} \%$ fiber composites which showed different properties. The addition of bagasse fiber significantly impacted on the Young's modulus of the starch films.

Jute is multi-celled in structure and is a lingo-cellulosic fiber as its chief chemical ingredients are cellulose and lignin [5]. It is usually derived from jute plant stem and grows to about $2.5-4.5 \mathrm{~m}$. Amongst various natural fibers, jute fibers are effortlessly obtainable in fabric forms with decent mechanical and thermal properties [6]. River flats, depressions and saline-alkali soils are most appropriate for the jute plantations [7].

Much work has been published concerning the reinforcing potential of jute fiber with polymer composites. There are several factors to be considered when designing the composite materials [8]. Gassan and Bledzki [9] calculated the improvement in mechanical properties of jute fibers reinforced thermoset resin composites considering several parameters. Gowda et al. [10] assessed the tensile behavior of jute-fabric reinforced polyester material in both the longitudinal and transverse directions. Mohanty et al. [11] considered the effect of jute fiber 
content on the tensile behavior of jute fabrics-polyester amide composites. Albuquerque et al. [12] evaluated the effect of fiber surface wettability, alkali treatment and different aging conditions on the tensile properties of longitudinally oriented jute reinforced polyester composites. Ray et al. [13] investigated the alkali treatment of jute fiber and composites in terms of tensile and flexural properties. Khondker et al. [14] considered the tensile behavior of unidirectional jute/polypropylene composites fabricated by the film stacking method. Cabral et al. [15] examined the mechanical response, water uptake and dielectric properties of short jute fiber-reinforced polypropylene composites. It was found that the Young's modulus and tensile strength monotonically amplified with increasing the fiber volume fraction, whereas the impact resistance increased up to a critical value of the fiber volume fraction and then declined.

Corrales et al. [16] studied the chemical modification of jute fibers using a fatty acid derivate (oleoyl chloride) to confer hydrophilicity and resistance to biofibers. Vilaseca et al. [17] evaluated the influence of the degree of adhesion at the fiber-matrix interface to the mechanical properties of the starch-based composites reinforced with jute strands. The alkali treatment was carried out for jute strands and the mechanical properties of the equivalent composite was determined. Akil et al. [18] considered the effects of water absorption (WA) on the mechanical properties of jute fiber reinforced with unsaturated polyester (UP). Das et al. [19] reported that the tensile strength of the biocomposite films (with 5, 10 and 15wt\% filler) increased by 51\%, 130\% and 197\%, respectively, in comparison to the unreinforced one, because of effective stress transfer at the interface between the constituents. Thitithanasarn et al. [20] investigated the reinforcement of commodity thermoplastics with various natural fibers. Hossain et al. [21] studied jute composites made with vacuum-assisted resin infiltration techniques showing different jute fiber preform stacking sequences. Hojo et al. [22] studied several kinds of composites with natural fiber mats as reinforcements (jute, kenaf and bamboo) and UP as the matrix.

This article presents the development of fully "green" untreated jute fiber composites based on a potato starch matrix. These composites are designed to obtain improved mechanical properties by modifying starch matrix (glycerol as plasticizer) with jute fiber. The aim of this investigation is to use a combination of natural fiber and starch, and fabricate biocomposites which would replace the expensive, hazardous or depleting materials.

\section{Experimental section}

\subsection{Materials}

Starch was used as the matrix material in the present study. Starch or amylum is a carbohydrate containing large numbers of glucose units linked by glycosidic bonds. It is the most common carbohydrate in human diets and is found in great amounts in staple foods as such potatoes, wheat, maize, rice and cassava. Pure starch is a white, tasteless and odorless powder that is insoluble in cold water or alcohol. Figure 1 shows the whitish appearance of starch. Different properties of starch are illustrated in Table 1. Starch consists of two types of molecules; the linear and helical amylose and the branched amylopectin. Depending on the plant, starch generally contains 20-25\% amylose and 75-80\% amylopectin by weight.

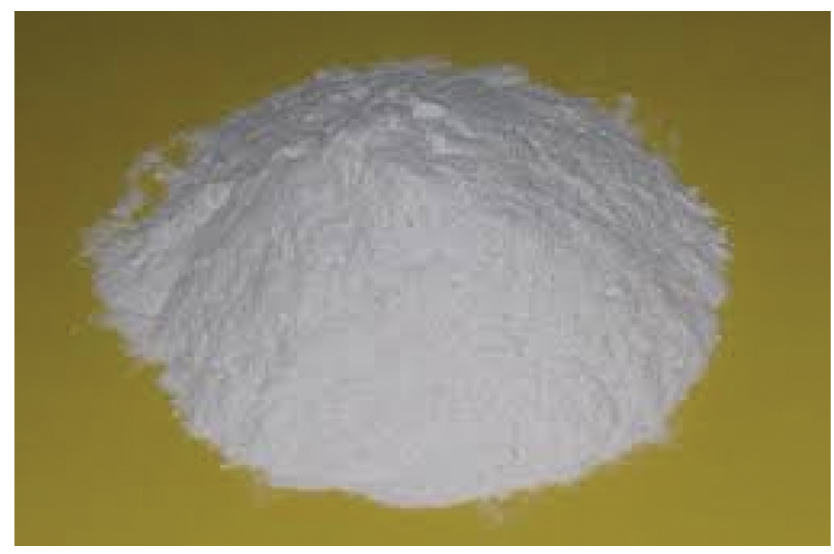

Figure 1: Starch.

Table 1: Properties of starch [23], https:/ /en.wikipedia.org/wiki/Starch]. 


$\begin{array}{ll}\text { Molar mass } & \text { Variable } \\ \text { Appearance } & \text { White powder } \\ \text { Density } & 1.5 \mathrm{~g} / \mathrm{cm}^{3} \\ \text { Solubility in water } & \text { Insoluble } \\ \text { Auto ignition temperature } & 410^{\circ} \mathrm{C} \\ \text { Classification } & \text { Carbohydrate }\end{array}$

Herein, potato starch was utilized that contains approximately $800 \mathrm{ppm}$ phosphate bound to the starch; this increases the viscosity and gives the solution a slightly anionic character, a low gelatinization temperature and a high swelling power.

Jute fiber was used as the reinforcing material in this study (Figure 2). The structure of the jute fiber is influenced by the climatic conditions, age and the fermentation process, which also influence its chemical composition (Table 2). The jute fiber holds moderately high specific strength and stiffness. Therefore, it is appropriate as a reinforcement in a polymeric resin matrix. Mechanical properties such as ultimate tensile strength (UTS) and initial modulus are related to the internal structure and chemical composition of fiber. Jute produced from plants of the genus Corchorus, is one of the cheapest natural fibers and is the fiber with the highest production volume in India, Bangladesh and China.

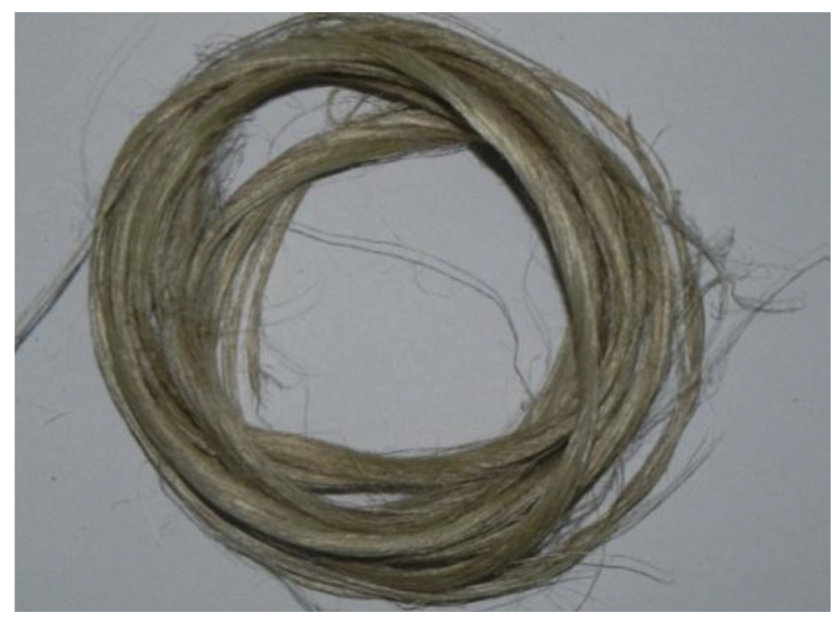

Figure 2: Raw jute fiber.

Table 2: Chemical composition of jute fiber [24].

Constituents (in \% of dry weight of the fiber)

Jute fiber is $100 \%$ biodegradable and recyclable and thus is environmental friendly. It is the cheapest natural fiber procured from the bast or skin of the plant's stem. It is the second most important natural fiber after cotton, in terms of usage, global consumption, production and availability. It has been used in raw materials for packaging, textiles, non-textile and agricultural sectors. It is also the most environment-friendly fiber starting from the seed to the expired fiber, as the expired fibers can be recycled more than once.

Glycerol was used as a plasticizer in the present study. Its function is to bind the starch molecules and water molecules strongly when heat is applied. Glycerol (glycerine/glycerin) is a simple polyol (sugar alcohol) compound, and is a colorless, odorless and viscous liquid. In this study, glycerol was produced as a co-product in the production of long-chain carboxylate salts used as soaps. The properties of glycerol are listed in Table 3. 
Table 3: Properties of glycerol [bib, https://en.wikipedia.org/wiki/Glycerol].

\begin{tabular}{ll}
\hline IUPAC name & Propane-1,2,3-triol \\
Molecular formula & $\mathrm{C}_{3} \mathrm{H}_{8} \mathrm{O}_{8}$ \\
Appearance & Colorless liquid hygroscopic \\
Odor & Odorless \\
Density & $1.261 \mathrm{~g} / \mathrm{cm}^{3}$ \\
Melting point & $17.8^{\circ} \mathrm{C}$ \\
Boiling point & $290^{\circ} \mathrm{C}$ \\
Viscosity & $1.412 \mathrm{~Pa}-\mathrm{s}$ \\
\hline
\end{tabular}

Citric acid (CA) is a weak organic (carboxylic) acid, which exists in greater than trace amounts in a variety of fruits and vegetables and due to its multi-carboxyl structure, it is recognized as a cross-linking agent for starch modification. CA was used in this study because it is recognized as nutritionally harmless as compared to other substances used for starch derivative. The properties of CA are shown in Table 4.

Table 4: Properties of citric acid [bib, https://en.wikipedia.org/wiki/Citric_acid].

\begin{tabular}{ll}
\hline IUPAC name & 2-hydroxypropane-1,2,3-tricarboxylic acid \\
Molecular formula & $\mathrm{C}_{6} \mathrm{H}_{8} \mathrm{O}_{7}$ \\
Molar mass & $192.12 \mathrm{~g} / \mathrm{mol}$ \\
Appearance & Crystalline white solid \\
Odor & Odorless \\
Density & $1.665 \mathrm{~g} / \mathrm{cm}^{3}$ \\
Melting point & $156^{\circ} \mathrm{C}$ \\
Boiling point & $310^{\circ} \mathrm{C}$ \\
\hline
\end{tabular}

Vinegar [acetic acid $\left(\mathrm{CH}_{3} \mathrm{COOH}\right)$ and water] was used in the present study as anti-bacterial and antifungal substance. It is produced by the fermentation of ethanol by acetic acid bacteria and is mainly used as a household cleanser.

Epoxy resin (Araldite CY-230) has wide range of industrial applications because of its high strength and mechanical adhesiveness characteristic. The physical and chemical properties of the epoxy resin are shown in Table 5 .

Table 5: Physical and chemical properties of the epoxy resin (CY-230).

\begin{tabular}{lll} 
S. No. & Epoxy resin (Araldite $\mathbf{C Y - 2 3 0 )}$ & \\
\hline 1. & Physical properties & $\begin{array}{l}\text { Yellow-brown colored, odorless, tasteless, nontoxic, low shrinkage } \\
\text { and density }=1150 \mathrm{~kg} / \mathrm{m}^{3} \\
\text { Product of reaction between bisphenol A and epichlorohydrin with } \\
\text { 2. }\end{array} \quad$ Cheme amount of toluene \\
3. & Chemical composition &
\end{tabular}

In the current inspection, epoxy resin (CY-230) [25], diglycidyl ether of bisphenol-A (DGEBA, EPON 828), purchased from M/s CIBATUL Limited (India) [26], was used as the matrix material. Hardener (HY-951) is a yellowish-green colored liquid and was also purchased from M/s CIBATUL Limited (India); and acted as a curing agent for the experimentation. In the present investigation, a mixture of 100 parts by weight of DGEBA and nine parts by weight of hardener (HY-951) was used in all the materials developed. The w $\mathrm{t} \%$ of the hardener used in the existing analysis is as per the reference of Singh and Gope [27].

\subsection{Methodology}

The methodology used in this study for preparing starch-jute composite was as per the authors' previous work on sisal fiber [23]; except the fiber used here was jute fiber.

i. Alkaline treatment:Firstly, the jute fibers were soaked in an alkaline solution of $2 \%$ sodium hydroxide $(\mathrm{NaOH})$, at a temperature of $22 \pm 2^{\circ} \mathrm{C}$ for $24 \mathrm{~h}$. The authors treated the jute fiber surface with $\mathrm{NaOH}$ 
(alkaline treatment) to boost the interfacial adhesion between the biological fibers and the polymers. Also, the alkaline treatment removeed a definite quantity of oil, wax and impurity that coats the exterior surface of fiber. It was then washed with distilled water and left to dry before being put in an oven for $15 \mathrm{~h}$ at $70^{\circ} \mathrm{C}$. Finally, the jute fibers were sliced into 2-3 mm length size.

ii. Solvent-cast film preparation method:Starch (30 g) and glycerol ( $~ 9.9 \mathrm{~g})$ were thoroughly mixed together; followed by adding $1000 \mathrm{ml}$ distilled water to this mixture. As an anti-bacterial substance $5 \mathrm{ml}$ of vinegar was used. This mixture was boiled while stirring for $1 \mathrm{~h}$, which was done on magnetic stirrer and allowed to cool to $75^{\circ} \mathrm{C}$, followed by casting on a nonstick tray and placed in a $65^{\circ} \mathrm{C}$ oven to dry. Finally, it was mixed with jute fibers and put in the mould. Starch solutions at the time of stirring and after stirring are shown in Figure 3 and Figure 4, respectively.

iii. Hot-pressed film preparation method:Cast films were crushed and then hydrated to $25 \mathrm{wt} \%$ moisture, and then allowed to equilibrate for $24 \mathrm{~h}$. Films were made by hot-pressing the hydrated material in a steel plate mould (dimensions of $90 \times 60 \times 1 \mathrm{~mm}^{3}$ ) at different temperature and pressure in a compression moulding machine.

iv. Epoxy coating:The jute fiber composite samples were dried at $80^{\circ} \mathrm{C}$ for $1 \mathrm{~h}$, prior to immersion in an epoxy resin bath (DGEBA). After 2 min of immersion, the samples were hung up and permitted to cure at room temperature for 2 days. Finally, the epoxy resin (CY-230) was deposited on the jute fiber composite sample [28].

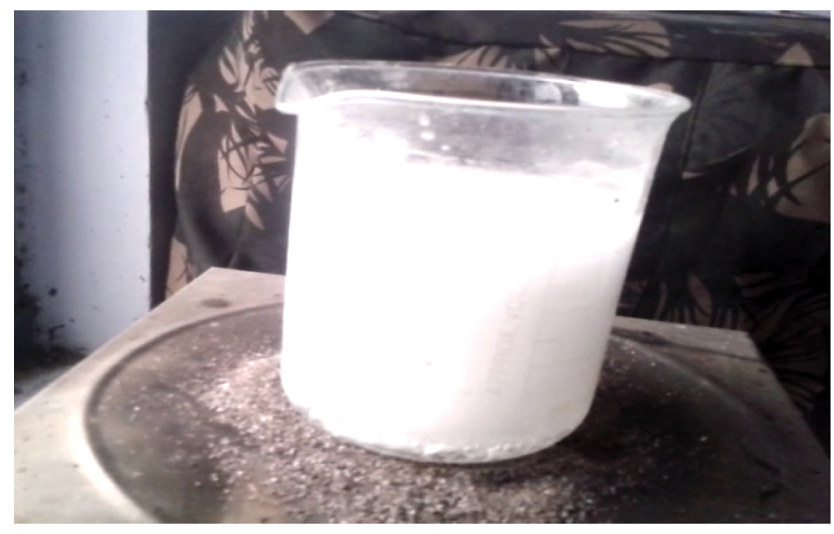

Figure 3: Starch solution at the time of stirring.

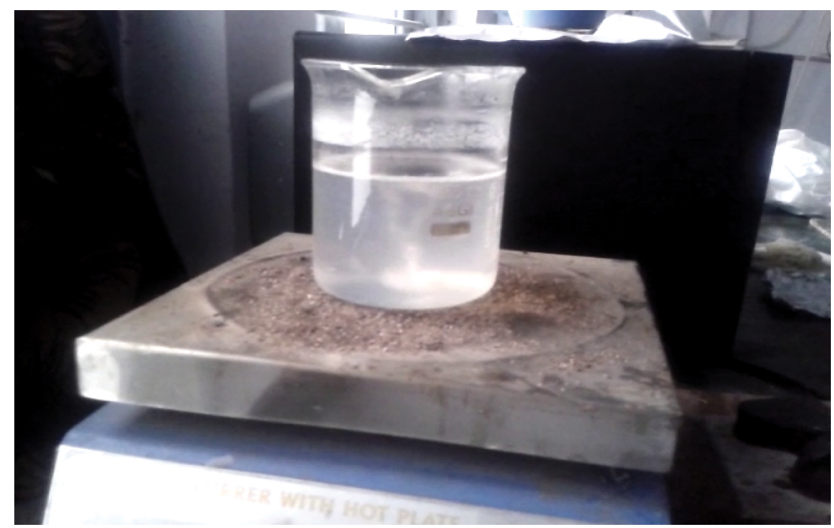

Figure 4: Starch solution after stirring.

\subsection{Characterization}

In this experiment, all the tensile tests were directed as per ASTM D638 and ASTM D3039 test procedures [29], [30]. According to these standards, dimensions of each test specimen were had a width of $25 \mathrm{~mm}$, a length of $250 \mathrm{~mm}$ and a thickness of $2.5 \mathrm{~mm}$ (Figure 5). The tests were conducted on a $100 \mathrm{kN}$ servo-hydraulic tensile testing machine (model 2008, ADMET, India) with a crosshead speed of $0.5 \mathrm{~mm} / \mathrm{min}$ [temperature $-30^{\circ} \mathrm{C}$ and relative humidity $(\mathrm{RH})-50 \%]$. 


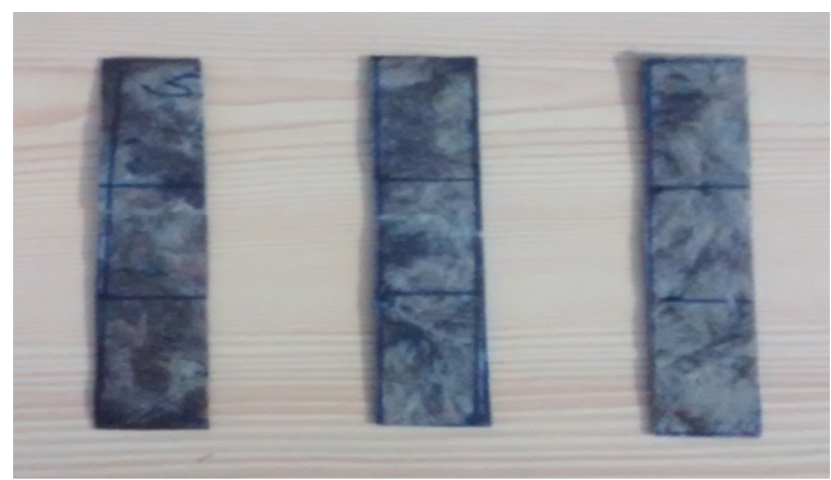

Figure 5: Tensile test specimens.

It is important to study the behavior of composites when they are exposed to environmental conditions such as temperature and humidity. The natural particle-reinforced composites are lightweight, reasonably strong, free from natural hazards and degradable with some disadvantages like poor moisture resistance and low strength compared to synthetic fibers. Tests were conducted under water soaking conditions. Specimens were immersed in water having a $\mathrm{pH}$ of 7.1. Specimens were first dried in oven and then submerged in water at room temperature. To determine the WA an electronic weighing machine (least count $0.001 \mathrm{~g}$ ) was used. Before each reading the surface of the specimen was wiped with a tissue paper. WA was calculated by the Eq. (1) [31]:

$$
\mathrm{WA}(\%)=\frac{\left(\mathrm{W}_{2}-\mathrm{W}_{1}\right)}{\mathrm{W}_{1}} \times 100
$$

where,

$\mathrm{W}_{1}$, initial specimen weight, in grams; $\mathrm{W}_{2}$, specimen weight after ' $\mathrm{N}$ ' hours of water soaking, in grams.

In this work, the scanning electron microscopy (SEM) study was done to see the dispersion of jute fiber in the biodegradable resin. The images were obtained through microscopic investigation with LEO435V6. To obtain SEM images square samples were cut from the cast material and were gold coated to avoid the artifacts associated with sample charging and then placed inside a chamber in which an electron beam with an accelerated voltage of $10 \mathrm{kV}$ fell on the material.

Thermal analysis (TA) is the branch of science where the properties of materials are studied as they change with temperature. In the TA section, thermo gravimetric analysis (TGA) and differential thermal analysis (DTA) were done. The TA was carried out using a thermo gravimetry (TG) analyzer (EXSTAR TG/DTA 6300) at IIT, Roorkee, by heating the samples in still air $(200 \mathrm{ml} / \mathrm{min})$ at $10^{\circ} \mathrm{C} / \mathrm{min}$ from $0^{\circ} \mathrm{C}$ to $250^{\circ} \mathrm{C}$. TG is the branch of thermal analysis which examines the mass change of a sample as a function of temperature in the scanning mode or as a function of time in the isothermal mode. TG is most useful for dehydration, decomposition, desorption and oxidation processes. Another widely used thermal method of analysis is DTA. In DTA, the temperature of a sample is compared with that of an inert reference material during a programmed change of temperature.

\section{Results and discussion}

The tensile test, the WA test, SEM and TGA/DTA were performed on starch-jute fiber based composite. Results for the above performed tests are discussed in subsequent section.

\subsection{Tensile test}

The tensile properties were carried out on $100 \mathrm{kN}$ ADMET-made servo-controlled universal testing machine at a fixed strain rate of $0.5 \mathrm{~mm} / \mathrm{min}$ under displacement control mode. Tensile tests were conducted for various compositions of jute fiber. Samples were prepared according to the ASTM D638 standard. Stress-strain curves obtained for different $\mathrm{wt} \%$ of jute fiber prepared by compression at different temperatures and pressures are shown in this section.

Figure 6 shows the stress-strain curve for samples prepared by compression at $60^{\circ} \mathrm{C}$ temperature and 70 bar pressure. Three samples containing $5 \mathrm{wt} \%, 10 \mathrm{wt} \%$ and $15 \mathrm{wt} \%$ of jute fiber are plotted. The tensile strength rises with increasing fiber content and the sample containing $15 \mathrm{wt} \%$ of jute fiber showed the maximum strength. 
The UTS obtained for the sample containing $15 \mathrm{wt} \%$ of jute fiber is $5.768 \mathrm{MPa}$, for $10 \mathrm{wt} \%$ of jute fiber is 3.375 $\mathrm{MPa}$ and for $5 \mathrm{wt} \%$ of jute fiber is $1.93 \mathrm{MPa}$; as compared to $1.78 \mathrm{MPa}$ for the neat starch matrix.

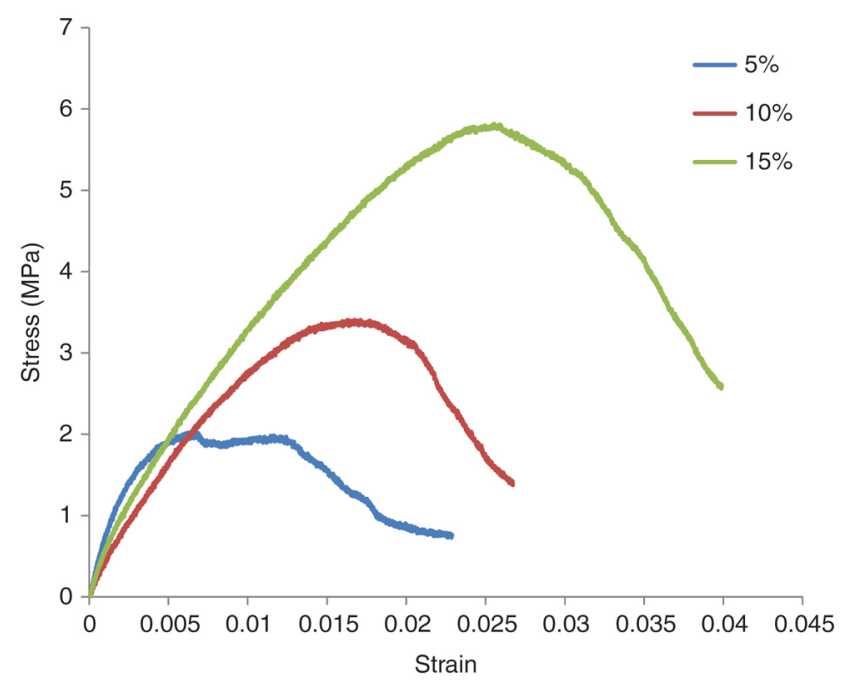

Figure 6: Stress-strain curve for samples prepared at $60^{\circ} \mathrm{C}$ temperature and 70 bar pressure.

Figure 7 shows the stress-strain curve for samples prepared by compression at $70^{\circ} \mathrm{C}$ temperature and 70 bar pressure. Three samples containing $5 \mathrm{wt} \%, 10 \mathrm{wt} \%$ and $15 \mathrm{wt} \%$ of jute fiber are plotted. The tensile strength is found to be maximum for a sample containing $15 \%$ fiber by weight. The UTS for samples containing $15 \mathrm{wt} \%$ of fiber is $7.547 \mathrm{MPa}$, for $10 \mathrm{wt} \%$ of fiber is $6.063 \mathrm{MPa}$ and for $5 \mathrm{wt} \%$ of fiber is $3.96 \mathrm{MPa}$.

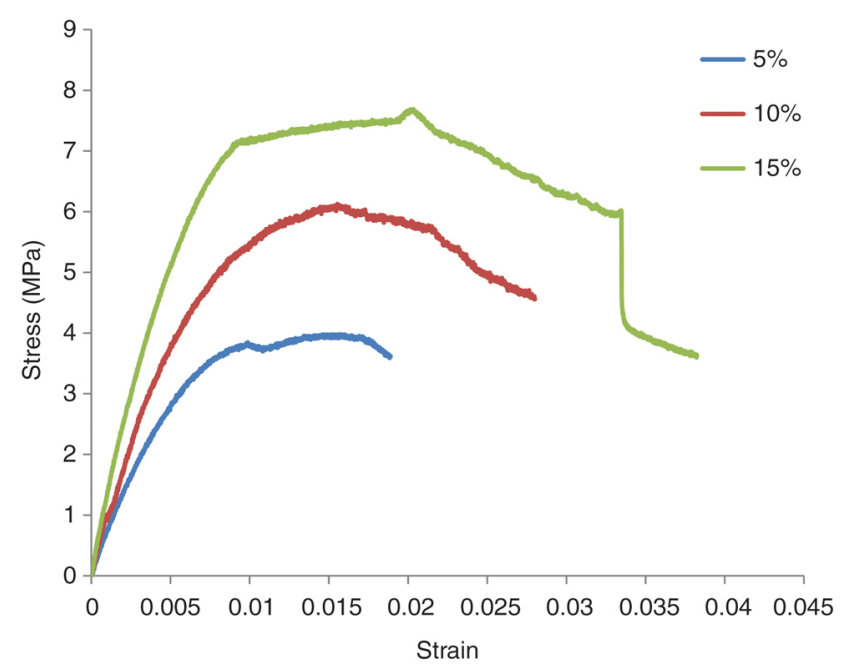

Figure 7: Stress-strain curve for samples prepared at $70^{\circ} \mathrm{C}$ temperature and 70 bar pressure.

Figure 8 shows the stress-strain curve for samples prepared by compression at $70^{\circ} \mathrm{C}$ temperature and $70 \mathrm{bar}$ pressure. Three samples containing $5 \mathrm{wt} \%, 10 \mathrm{wt} \%$ and $15 \mathrm{wt} \%$ of jute fiber are plotted. The UTS obtained for sample containing $15 \mathrm{wt} \%$ of fiber is $6.592 \mathrm{MPa}$, for $10 \mathrm{wt} \%$ of fiber is $4.147 \mathrm{MPa}$ and for $5 \mathrm{wt} \%$ of fiber is 3.147 MPa. 


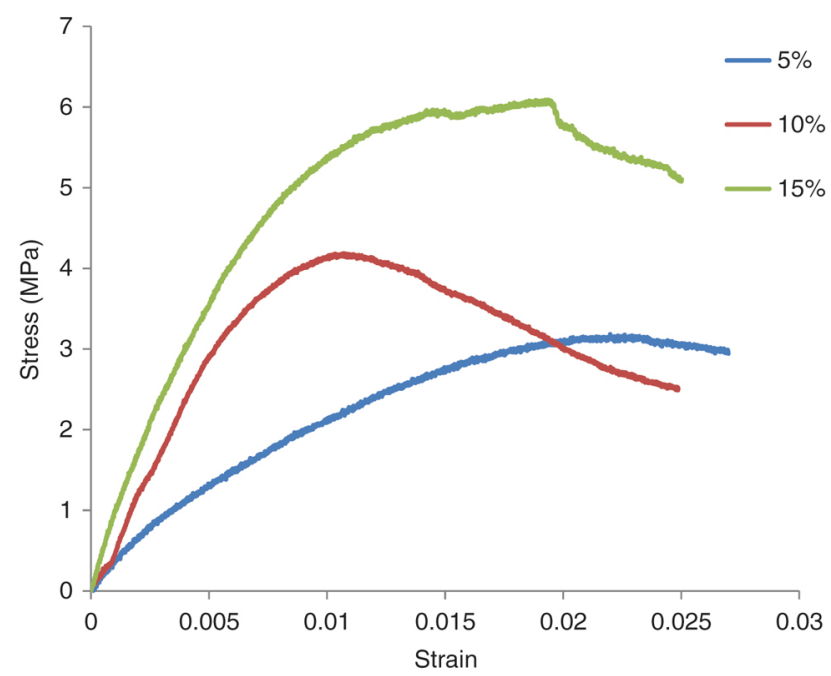

Figure 8: Stress-strain curve for samples prepared at $80^{\circ} \mathrm{C}$ temperature and 70 bar pressure.

Figure 9 shows the stress-strain curve for samples prepared by compression at $90^{\circ} \mathrm{C}$ temperature and 70 bar pressure. Three samples containing $5 \mathrm{wt} \%, 10 \mathrm{wt} \%$ and $15 \mathrm{wt} \%$ of jute fiber are plotted. The UTS obtained for samples containing $15 \mathrm{wt} \%$ of fiber is $6.58 \mathrm{MPa}$, for $10 \mathrm{wt} \%$ of fiber is $6.05 \mathrm{MPa}$ and for $5 \mathrm{wt} \%$ of fiber is $2.803 \mathrm{MPa}$. From these performed tests, it can be concluded that the highest UTS was shown by the samples prepared at $70^{\circ} \mathrm{C}$ temperature and 70 bar pressure with UTS $=7.547 \mathrm{MPa}$ (for samples containing $15 \%$ jute fiber by weight). Therefore, the samples prepared at $70^{\circ} \mathrm{C}$ temperature and 70 bar pressure were considered for further investigation.

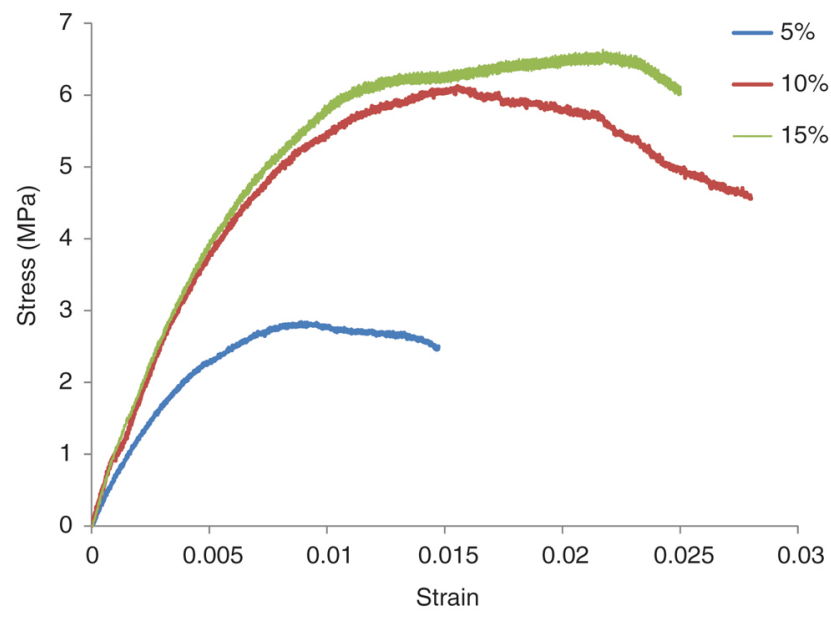

Figure 9: Stress-strain curve for samples prepared at $90^{\circ} \mathrm{C}$ temperature and 70 bar pressure.

As already stated, these natural composites lack the capability to resist moisture in the environment. That is why the authors considered an epoxy resin coating over it. Samples containing $5 \mathrm{wt} \%, 10 \mathrm{wt} \%$ and $15 \mathrm{wt} \%$ jute fiber and prepared by compression at $70^{\circ} \mathrm{C}$ temperature and 70 bar pressure were coated with a thin layer of epoxy. The tensile test was then performed on the samples containing a thin layer of epoxy. Figure 10 shows the graph plotted between stress and strain. The UTS obtained for sample containing $15 \mathrm{wt} \%$ of fiber is $10.46 \mathrm{MPa}$, for $10 \mathrm{wt} \%$ of fiber is $10.28 \mathrm{MPa}$ and for $5 \mathrm{wt} \%$ of fiber is $4.68 \mathrm{MPa}$. 


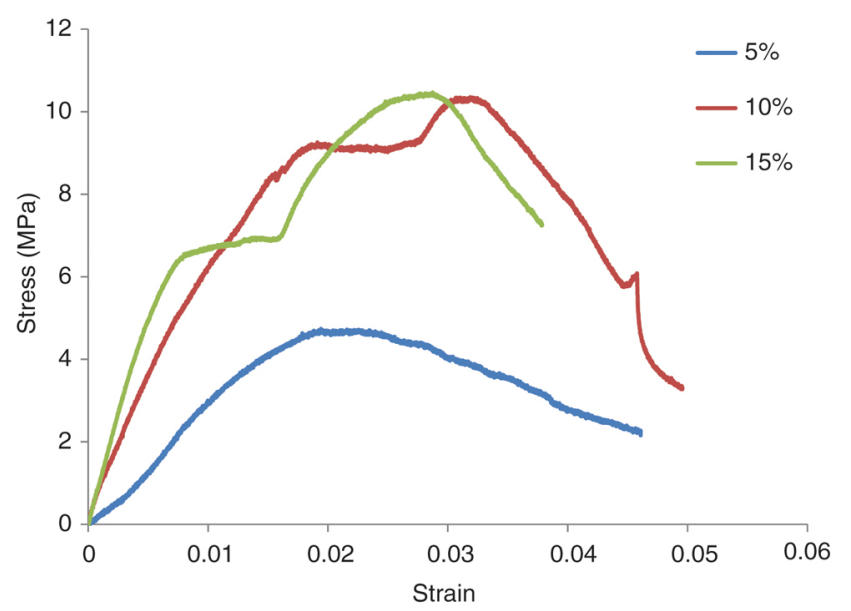

Figure 10: Stress-strain curve for samples prepared at $70^{\circ} \mathrm{C}$ temperature and 70 bar pressure with epoxy coating.

Figure 11 shows a comparison between UTS and wt $\%$ of fiber composites. Three samples containing 5\%, $10 \%$ and $15 \%$ jute fiber by weight with epoxy coating and without coating of epoxy (samples prepared at $70^{\circ} \mathrm{C}$ temperature and 70 bar pressure) are plotted. The UTS for samples containing $15 \mathrm{wt} \%$ of fiber is $10.46 \mathrm{MPa}$, for $10 \mathrm{wt} \%$ of fiber is $10.28 \mathrm{MPa}$ and for $5 \mathrm{wt} \%$ of fiber is $4.68 \mathrm{MPa}$ with epoxy coating and the UTS for samples containing $15 \mathrm{wt} \%$ of fiber is $7.547 \mathrm{MPa}$, for $10 \mathrm{wt} \%$ of fiber is $6.063 \mathrm{MPa}$ and for $5 \mathrm{wt} \%$ of fiber is $3.96 \mathrm{MPa}$ without epoxy coating. It can be clearly seen from the graph that the UTS for samples containing epoxy coating is higher than the samples without the epoxy coating.

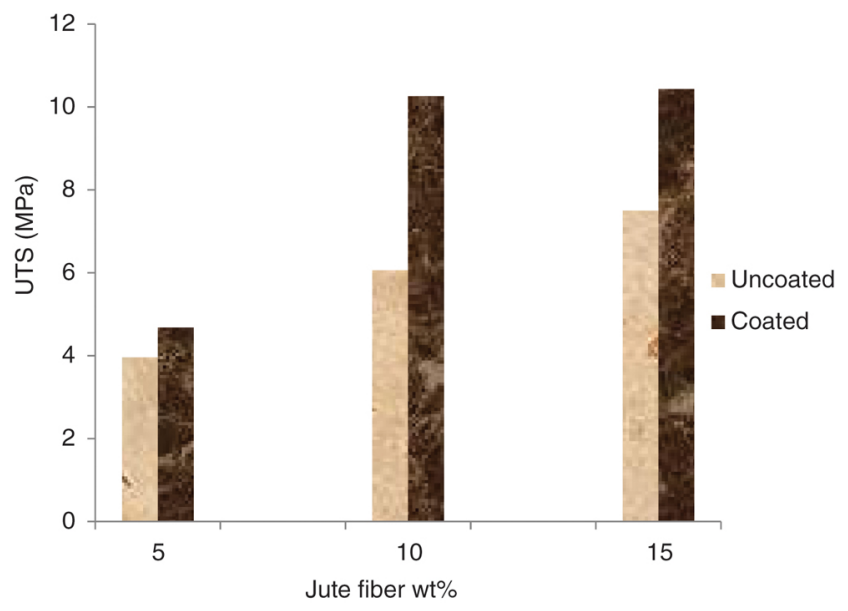

Figure 11: UTS for coated and uncoated samples.

As can be seen from the Figure 11, the UTS for samples without epoxy coating $(5 \%, 10 \%$ and $15 \%$ jute fiber by weight) rises gradually. For samples with the epoxy coating the UTS is higher than the samples without the epoxy coating. However, for samples $10 \%$ fiber by weight and $15 \%$ fiber by weight the difference in the UTS is not much. The rise in the UTS of samples coated with epoxy resin is due to the absorption of epoxy and enhanced cross-linking that occurs between the epoxy and starch molecules. The absorption of epoxy resin depends upon two factors: (i) the number of voids present in the matrix, and (ii) the absorption of epoxy resin by the fiber. At $5 \mathrm{wt} \%$ of fiber the voids in the matrix of composite are low and also the fiber content is low, hence the increase in the UTS is not much. At $10 \mathrm{wt} \%$ of fiber, the number of voids in the matrix increase and also the fiber content rises; therefore, the sample absorbs more resin and hence the strength improves significantly. At $15 \mathrm{wt} \%$ of fiber, the amount of fiber in the matrix is very high due to which, the space available for absorption of epoxy is not enough. Hence, the strength of the sample rises; but, the increase is not as high as it was for the sample containing $10 \mathrm{wt} \%$ of fiber. Table 6 shows the comparison of UTS for samples without epoxy coating and with epoxy coating.

Table 6: Comparison of UTS for uncoated and coated samples. 


\subsection{Water absorption test}

The WA test provides information about the adhesion between the fibers and matrix in the interface region. The WA test was done by dipping all the samples in water and then weighing them in time intervals of 10 min. Figure 12 shows the WA\% for samples without epoxy coating. As expected the prepared green composite has a highly hydrophilic character which was confirmed by the WA test. It can be observed from the figure that in the beginning the WA for samples $(5 \mathrm{wt} \%, 10 \mathrm{wt} \%$ and $15 \mathrm{wt} \%$ of jute fiber) without coating is very high. The rate of absorption of the water decreases with time of immersion of the sample in water. WA increases with increasing the fiber content as jute is highly hydrophilic; hence, the increase of WA with increasing fiber content is justified.

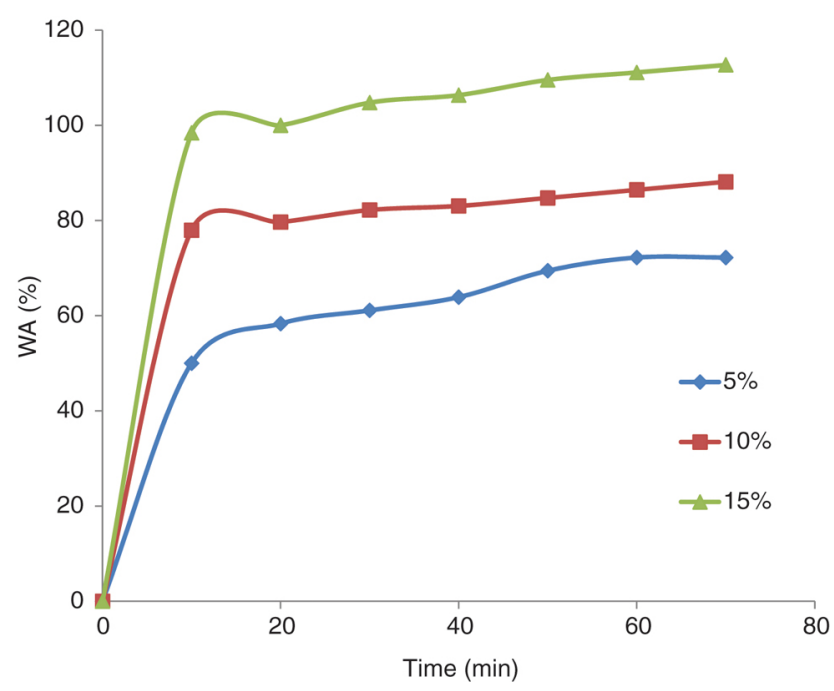

Figure 12: WA for samples without epoxy coating.

Figure 13 shows the WA\% for samples with the epoxy coating. As can be observed from the graph the rate of WA has slowed down for different wt $\%$. The amount of WA as well as the high rate of absorption has been controlled to a large extent. Figure 14 shows the WA\% for all samples (coated and uncoated).

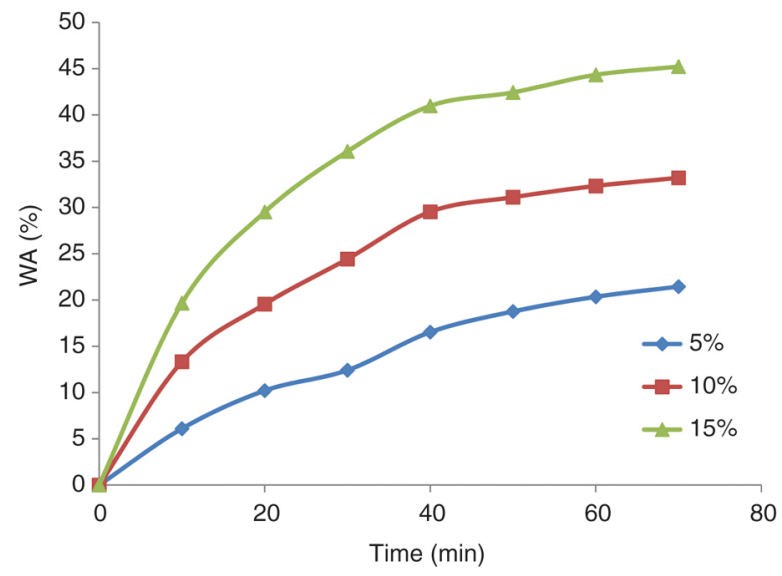

Figure 13: WA for samples with epoxy coating. 


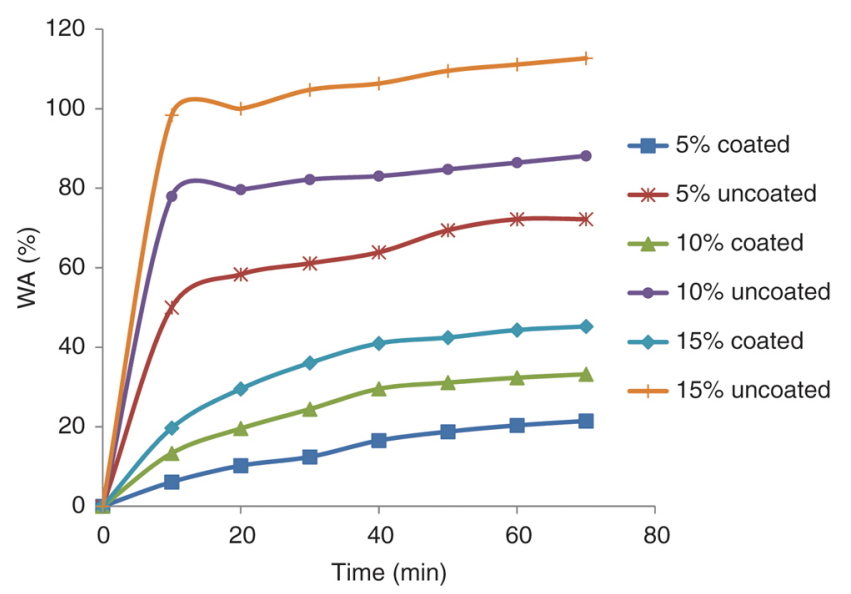

Figure 14: WA of all the samples (coated and uncoated).

Figure 15 shows the comparison between the water absorbed by different $w \mathrm{t} \%$ of jute fiber for samples without and with the epoxy coating. As can be concluded from the WA test, a thin coating of epoxy reduces the WA by a large amount. Water absorbed by the sample without the epoxy coating is very high, for $5 \mathrm{wt} \%$ of fiber it is $72.22 \%$, for $10 \mathrm{wt} \%$ of fiber it is $88.13 \%$ and for $15 \mathrm{wt} \%$ of fiber it is $112.69 \%$. WA for samples prepared with an epoxy coat is low as compared to the samples prepared without the epoxy coat. WA for coated samples containing $5 \%$ fiber by weight is $21.45 \%$, for $10 \%$ fiber by weight is $33.21 \%$ and for $15 \%$ fiber by weight is $45.23 \%$. Reduction in WA for $15 \mathrm{wt} \%$ sample is $149 \%$, for $10 \mathrm{wt} \%$ sample is $165.37 \%$ and for sample containing $5 \mathrm{wt} \%$ is $236.68 \%$.

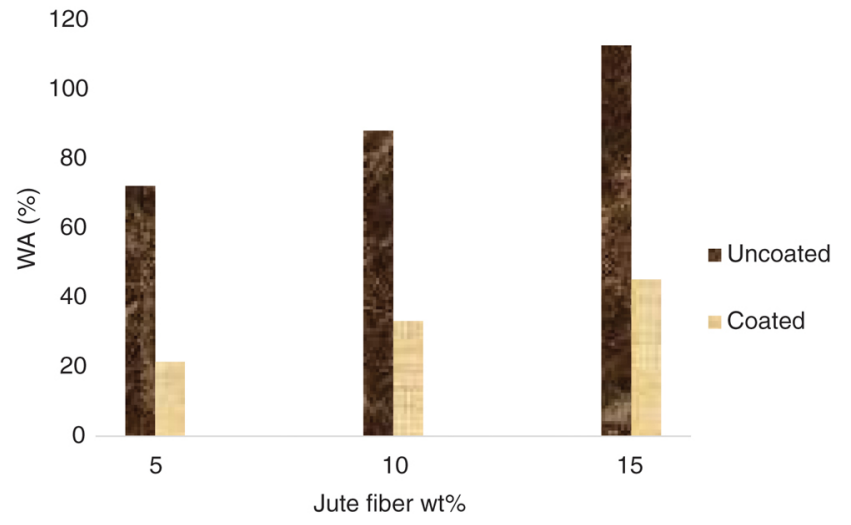

Figure 15: Maximum WA for uncoated and coated samples.

\subsection{SEM analysis}

The cross-sectional views of the fabricated green composite material consisting of starch, different wt $\%$ of jute fiber, are presented in Figure 16-Figure 23. The SEM images are taken to observe the interfacial properties, internal cracks and the internal structure of the fractured surfaces of composite materials. Figure 16-Figure 23 show the SEM photographs of surfaces of different composite materials investigated in the present work fractured under the tensile loading. Figure 16-Figure 18 show the SEM of $15 \mathrm{wt} \%$ jute fiber composite material with coating at a magnification of 500x, 100xand 50x, respectively. Figure 19 shows the SEM for $10 \mathrm{wt} \%$ jute fiber composite material with coating at $100 \times$ magnification. Figure 20 shows the SEM for $5 w t \%$ jute fiber composite material with coating at $50 \times$ magnification. Figure 21 shows the SEM for $15 \mathrm{wt} \%$ jute fiber composite material without coating at $500 \times$ magnification. Figure 22 shows the SEM for $10 \mathrm{wt} \%$ jute fiber composite material without coating at $100 \times$ magnification. Figure 23 shows the SEM for $5 \mathrm{wt} \%$ jute fiber composite material without coating at $100 \times$ magnification. 


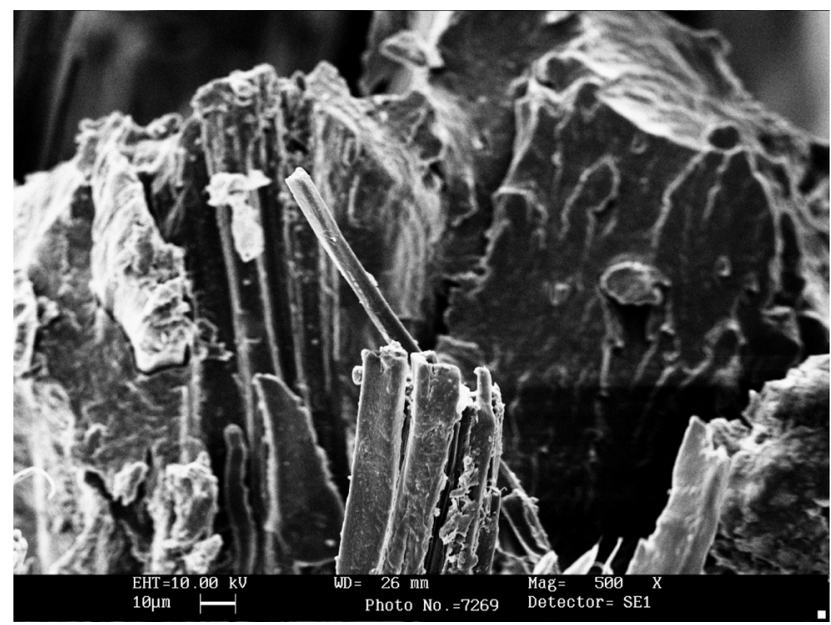

Figure 16: SEM for (15\% jute fiber by weight) composite material with coating at $500 \times$.

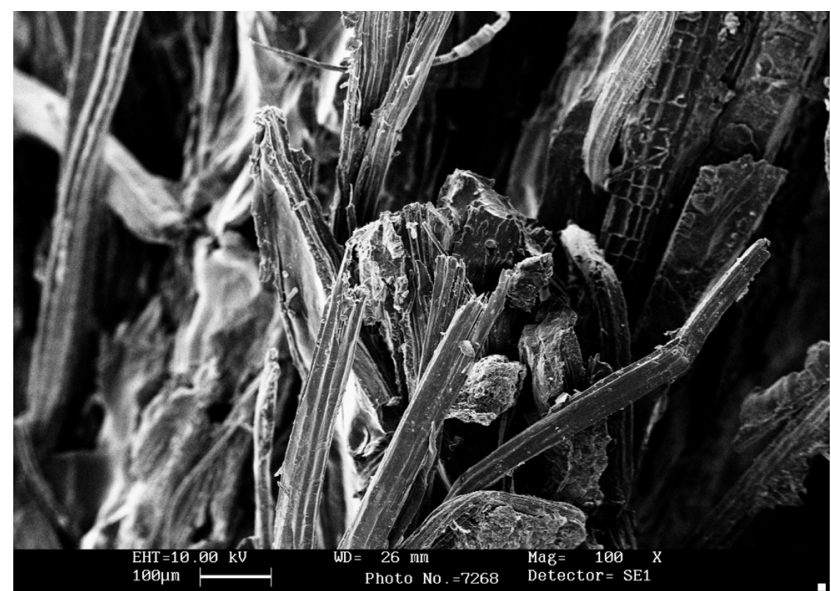

Figure 17: SEM for (15\% jute fiber by weight) composite material with coating at $100 \times$.

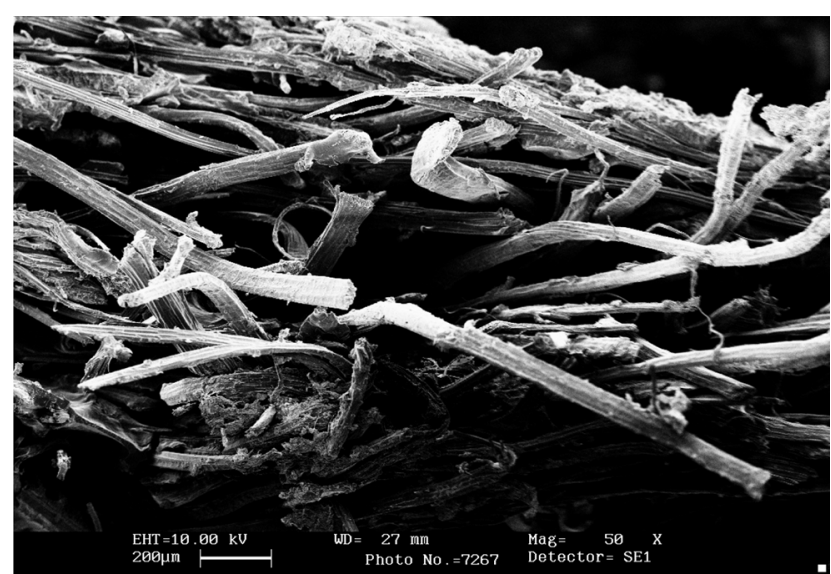

Figure 18: SEM for (15\% jute fiber by weight) composite material with coating at $50 \times$. 


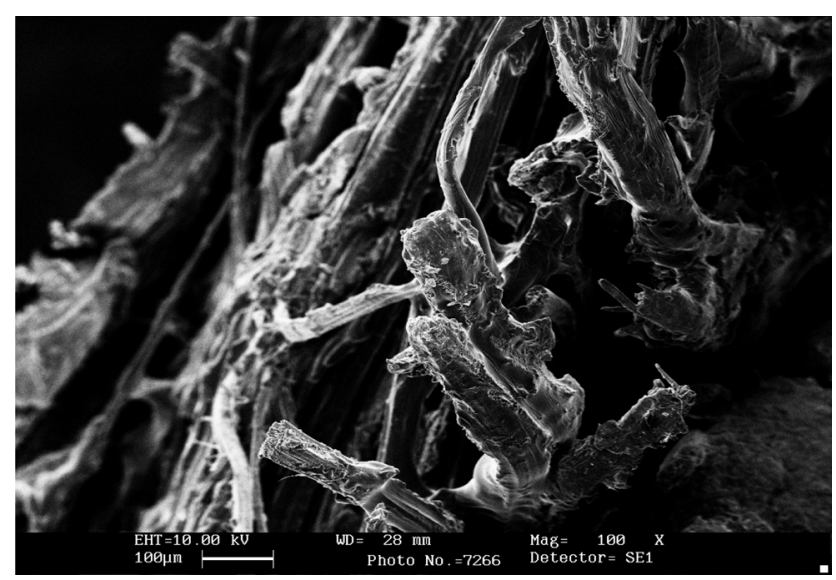

Figure 19: SEM for (10\% jute fiber by weight) composite material with coating.

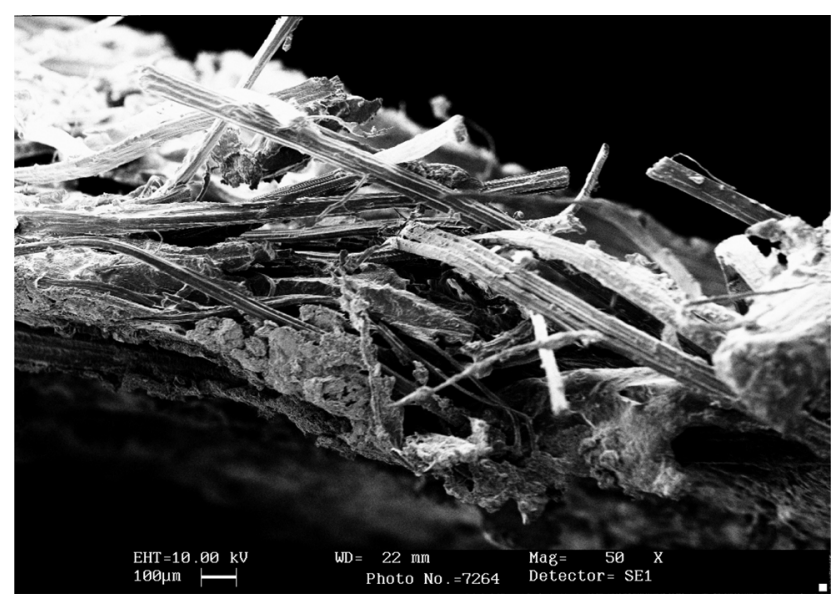

Figure 20: SEM for (5\% jute fiber by weight) composite material with coating.

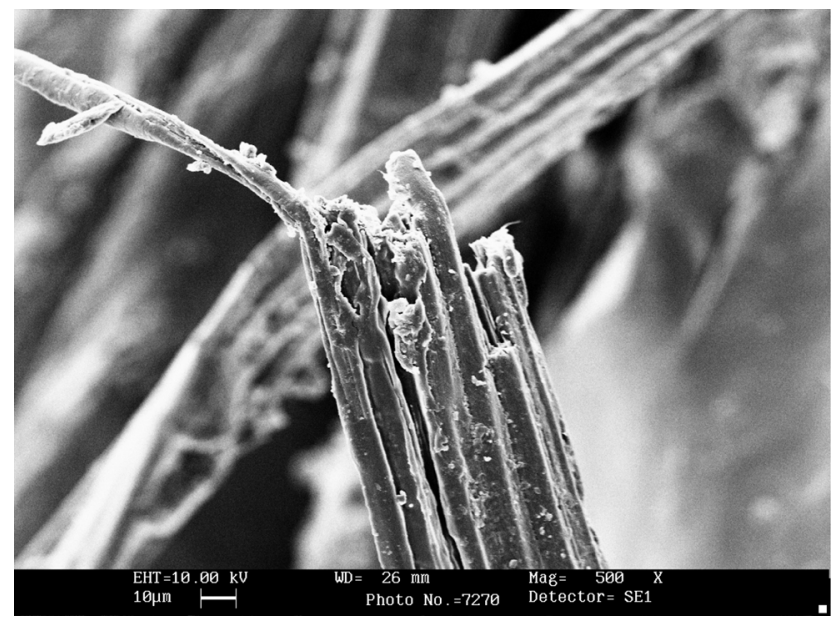

Figure 21: SEM for (15\% jute fiber by weight) composite material without coating. 


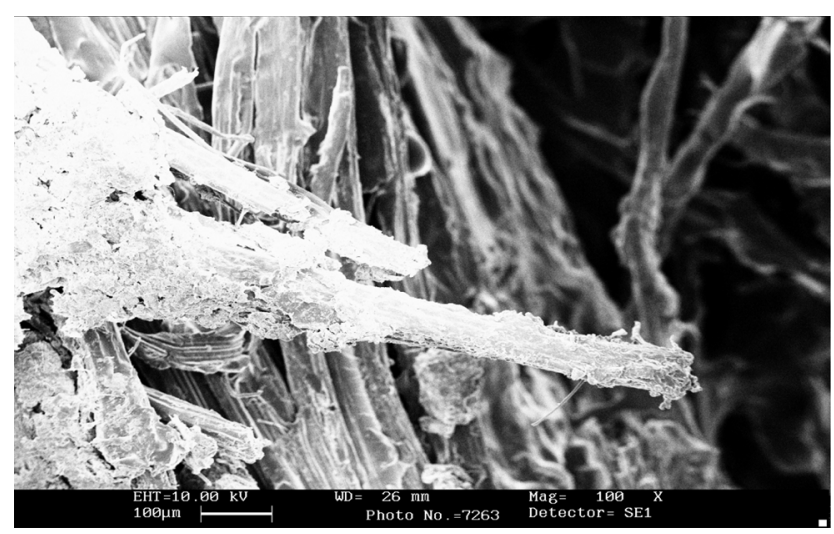

Figure 22: SEM for (10\% jute fiber by weight) composite material without coating.

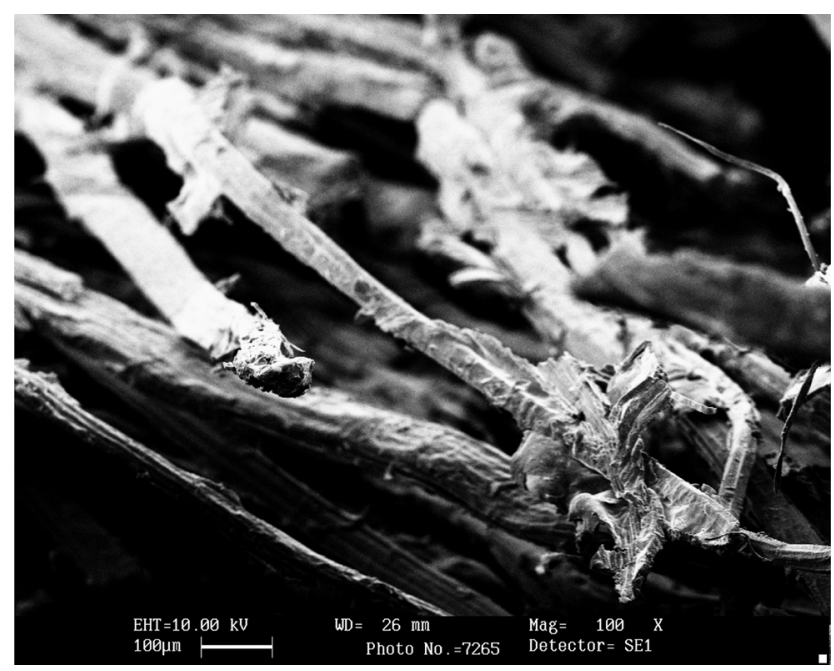

Figure 23: SEM for (5\% jute fiber by weight) composite material without coating.

Figure 16-Figure 18 show the fractured surface of $15 \mathrm{wt} \%$ fiber with coating of epoxy at a magnification of $500 \times, 100 \times$ and $50 x$, respectively. As it can be seen from these figures that due to higher wt $\%$ of fiber in the matrix, more fibers can be seen on the fractured surface. The higher $w \mathrm{t} \%$ of fiber has increased the tensile strength of the composite as compared to the strength of uncoated material. In Figure 18, the tangling of the fibers in the matrix due to higher $\mathrm{wt} \%$ is clearly visible. Figure 19 shows the fractured surface of $10 \mathrm{wt} \%$ of fiber coated with the epoxy at a magnification of $100 \times$. Due to low wt $\%(10 \mathrm{wt} \%)$ of fiber, it can be seen that the tangling of fibers is low as compared to sample containing higher $(15 \mathrm{wt} \%)$ fiber content. Figure 20 shows the fractured surface of $5 \mathrm{wt} \%$ of fiber coated with epoxy at a magnification of $50 \times$. As can be perceived from this figure, the fibers are not evenly distributed and the bonding with the matrix is low which leads to reduced strength. Figure 21 shows the fractured surface of $15 \mathrm{wt} \%$ fiber composite without the coating of the epoxy at a magnification of $500 \times$. As can be seen due to high fiber content clusters of fibers are formed. The interaction between the matrix and fibers is reduced and all the fibers do not bond with the matrix instead forming clusters of fibers leading to reduced tensile strength in comparison to the coated material of same $w t \%$. This formation of clusters leads to the accumulation of fibers in the matrix; thereby, reducing the UTS. Figure 22 shows the fractured surface of $10 \mathrm{wt} \%$ fiber composite without the coating at a magnification of $100 \times$. The surface is not so good and the fibers are not arranged in a proper way, so that the tensile strength is reduced in comparison to coated material of the same $w t \%$. Figure 23 shows the fractured surface of $5 \mathrm{wt} \%$ fiber composite with the coating at a magnification of 100x. The fiber content is very low (clearly evident from the image) which makes the bonding amongst fibers and matrix weak. Hence, the tensile strength in comparison to the coated material is low.

\subsection{Thermal analysis}

TA has been done for the sample with an epoxy coating containing $15 \%$ jute fiber by weight. For TA, the samples were prepared in powder form by crushing them and the weight of samples were nearly $10.44 \mathrm{mg}$. The base material was alumina powder, which was mixed with composite samples in equal amounts and the medium in 
which the tests were conducted was air flowing at $200 \mathrm{ml} / \mathrm{min}$. The rate of change of temperature was $10^{\circ} \mathrm{C} / \mathrm{min}$ and range of temperature was room temperature to $250^{\circ} \mathrm{C}$. Figure 24 shows the thermo gram of starch-jute fiberbased composite coated with the epoxy. Decomposition of this material was accomplished at $181^{\circ} \mathrm{C}$. The rate of decomposition of the material is $109 \mu \mathrm{g} / \mathrm{min}$. Prior to $150^{\circ} \mathrm{C}$, the weight loss of $6.5 \%$ may be attributed to the expulsion of the moisture, low molecular mass molecules and volatile matter associated with the material. In the initial stage of decomposition material absorbs energy (upto $50^{\circ} \mathrm{C}$ ) and after that it releases energy as revealed by the DTA curve. The decomposition of the material has been concluded at $252^{\circ} \mathrm{C}$ leaving the material $78.83 \%$ of the initial weight.

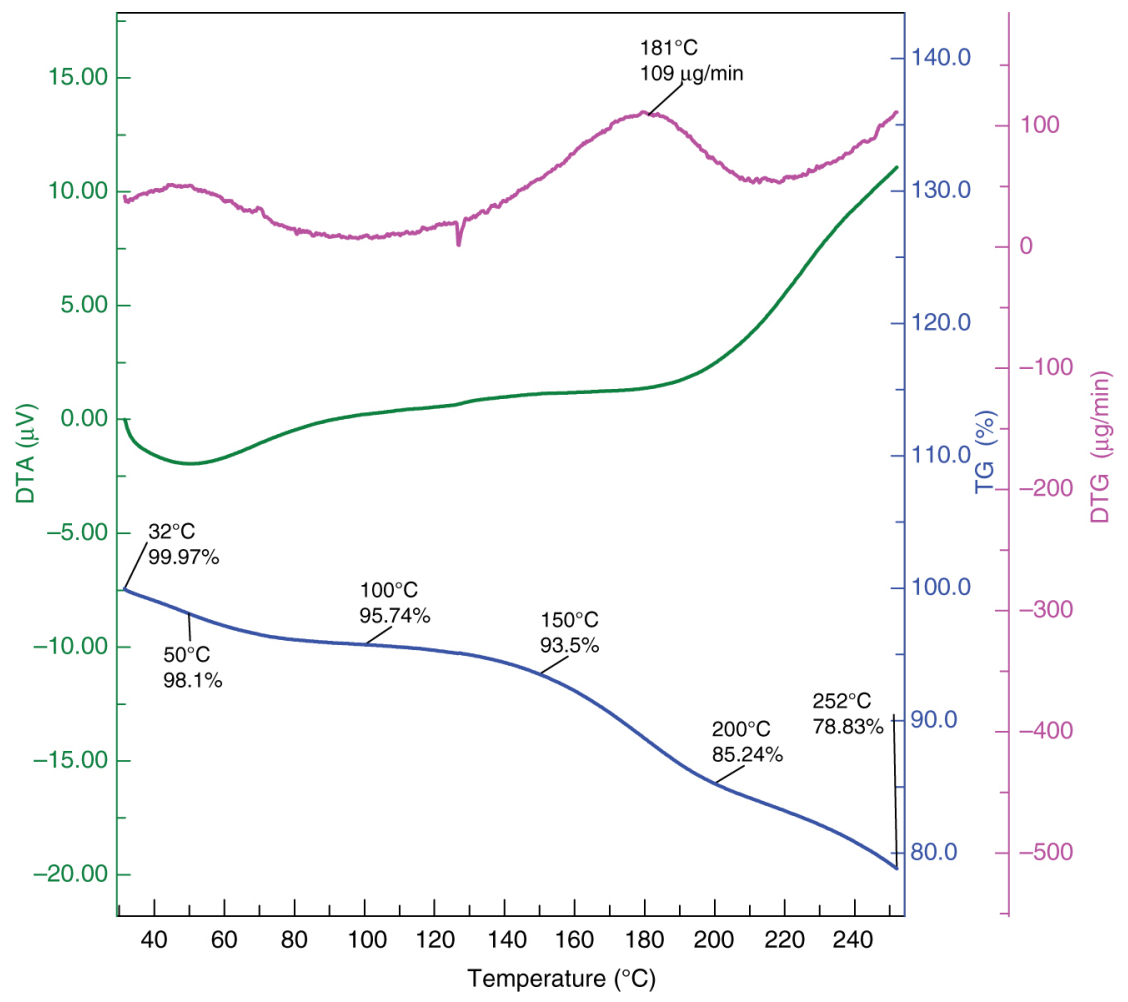

Figure 24: Thermal analysis of coated sample (15\% fiber by weight).

\section{Conclusions}

These experimental investigations on jute fiber filled starch bio-composite have led to the following conclusions:

1. Successful fabrication of a jute fiber filled starch composite with the hand lay-up technique followed by compression is possible.

2. Addition of jute fiber to the starch matrix has improved its UTS. Highest tensile strength was shown by the composite containing $15 \%$ fiber by weight. The prepared composite has very low density and is lightweight.

3. The green composite prepared has very high WA due to the highly hydrophilic character of both jute fiber and starch. With increasing the fiber content, the WA rises gradually and the composite containing the highest fiber content shows maximum WA.

4. Coating the prepared composite with a thin layer of epoxy further enhances the UTS and also reduces the WA by a large amount.

5. Through SEM, we could actually see the fibers dispersion in the matrix and their bonding with it. At higher ${ }_{w} \mathrm{t} \%$, fibers form clusters and affect the bonding; and also reveal the composite failure due to fiber pull out and splitting of fiber increases.

6. Thermal analysis reveals that the decomposition of the material is achieved at $181^{\circ} \mathrm{C}$ and the maximum rate of decomposition of the material is $109 \mu \mathrm{g} / \mathrm{min}$. 


\section{Acknowledgment}

Financial support from the G. B. Pant University of Agriculture and Technology, Pantnagar, India is gratefully acknowledged.

\section{References}

[1] Verma A, Parashar A, Packirisamy M. Wiley Interdiscip. Rev. Comput. Mol. Sci. 2017, 8 (3), e1346.

[2] Bogren KM, Gamstedt EK, Neagu RC, AÅkerholm M, LindstroÖm, M. J. Thermoplast. Compos. Mater. 2006, 19 (6), $613-637$.

[3] Cao Y, Shibata S, Fukumoto I. Compos. Part A: Appl. Sci. Manuf. 2006, 37 (3), 423-429.

[4] Gilfillan WN, Nguyen DM, Sopade PA, Doherty WO. Ind. Crop. Prod. 2012, 40, 45-54.

[5] Con D, Das K, Paul P, Maity S. International Journal of Textile Science, 2012, 1 (6), 84-93.

[6] Cujjala R, Ojha S, Acharya SK, Pal SK. J. Compos. Mater. 2014, 48 (28), 3445-3455.

[7] Liu L, Yu ], Cheng L, Yang X. Polym. Degrad. Stab. 2009, 94 (1), 90-94.

[8] Zhao Q, Hoa SV, Gao Z]. Sci. Eng. Compos. Mater. 2011, 18, 35-49.

[9] Gassan ], Bledzki AK. Compos. Sci. Technol. 1999, 59, 1303-1309.

[10] Cowda TM, Naidu ACB, Chhaya R. Compos. Part A: Appl. Sci. Manuf. 1999, 30 (3), 277-284.

[11] Mohanty AK, Khan MA, Hinrichsen G. Compos. Part A: Appl. Sci. Manuf. 2000, 31 (2), 143-150.

[12] De Albuquerque AC, Joseph K, de Carvalho LH, d'Almeida JRM. Compos. Sci. Technol. 2000, 60 (6), 833-844.

[13] Ray D, Sarkar BK, Rana AK, Bose NR. Bull. Mater. Sci. 2001, 24 (2), 129-135.

[14] Khondker OA, Ishiaku US, Nakai A, Hamada H. J. Polym. Environ. 2005, 13 (2), 115-126.

[15] Cabral H, Cisneros M, Kenny JM, Vazquez A, Bernal CR. J. Compos. Mater. 2005, 39 (1), 51-65.

[16] Corrales F, Vilaseca F, Llop M, Cirones ], Mendez JA, Mutje P. J. Hazard. Mater. 2007, 144 (3), 730-735.

[17] Vilaseca F, Mendez JA, Pelach A, Llop M, Canigueral N, Girones ], Turon X, Mutje P. Process Biochem. 2007, 42 (3), 329-334.

[18] Akil HM, Cheng LW, Ishak ZM, Bakar AA, Rahman MA. Compos. Sci. Technol. 2009, 69, 1942-1948.

[19] Das K, Ray D, Bandyopadhyay NR, Sahoo S, Mohanty AK, Misra M. Compos. B Eng. 2011, 42 (3), 376-381.

[20] Thitithanasarn S, Yamada K, Ishiaku US, Hamada H. Open Journal of Composite Materials. 2012, 2 (4), 133.

[21] Hossain MR, Islam MA, Van Vuurea A, Verpoest I. Procedia Eng. 2013, 56, 782-788.

[22] Hojo T, Xu Z, Yang Y, Hamada H. Energy Procedia 2014, 56, 72-79.

[23] Verma A, Gaur A, Singh VK. Materials Performance and Characterization 2017, 6, 500-520.

[24] Roul C. "The international jute commodity system," Northern Book Centre, 2009.

[25] Verma A, Singh VK. J. Test. Eval. 2019, 47 (2), 1-23.

[26] Verma A, Singh VK, Md. Arif. Research \& Reviews: ]. Mater. Sci. 2016, 4 (3), doi: 10.4172/2321-6212.1000146.

[27] Singh VK, Gope PC. J. Reinf. Plast. Compos. 2010, 29 (16), 2450-2468.

[28] Verma A, Singh VK. J. Mater. Sci. Eng. 2016, 5. doi:10.4172/2169-0022.1000242.

[29] ASTM D638-14, Standard Test Method for Tensile Properties of Plastics, Annual Book of ASTM Standards, ASTM International, West Conshohocken, PA, 2014.

[30] ASTM D3039/D3039M-14, Standard Test Method for Tensile Properties of Polymer Matrix Composite Materials, Annual Book of ASTM Standards, ASTM International, West Conshohocken, PA, 2014.

[31] Liu W, Hoa SV, Pugh M. Compos. Sci. Technol. 2008, 68 (9), 2066-2072. 